\title{
Use of thermometers in general practice
}

\author{
Steven Clarke
}

\begin{abstract}
Objective-To identify the attitudes of general practitioners towards the use of thermometers in general practice.

Design-Postal questionnaire survey.

Setting-All general practitioners in the catchment area of Frimley Park Hospital, Surrey.

Subjects -145 general practitioners.

Main outcome measures-Answers to questions covering a variety of aspects concerning the use of thermometers in general practice.

Results $-116(80 \%)$ doctors replied. Seven doctors did not have any method of taking a patient's temperature; up to 12 more doctors did not use their thermometers and 56 doctors used them infrequently, less than once a fortnight. Mercury glass thermometers were most commonly used ( 80 doctors; $69 \%$ ), but only $8 \%$ of doctors used them correctly. Six doctors failed to clean their thermometers between patients. The study failed to identify the roles of axillary and rectal temperature readings.
\end{abstract}

Conclusion-There is a wide variation in attitudes towards the use of thermometers in general practice.

\section{Introduction}

Many doctors would agree that the presence of a fever and its pattern and magnitude can give valuable clues as to the nature and severity of a patient's illness. In hospital medicine, for example, many ward rounds would be incomplete without the routine scanning of temperature charts at the end of the patient's bed

As a general practitioner trainee I was conscious that both my emergency bag and my consulting room lacked a thermometer. This did not seem to be a problem until I was faced with a patient who seemed quite unwell but for whom I could not give an explanation. After deciding that a temperature reading might prove helpful, I went hunting for a thermometer and discovered that not all the partners in the practice believed in their value.

Many clinical signs and symptoms can suggest the presence of a fever, but it is not known how much importance a general practitioner gives to actual thermometer readings. This study evaluates the attitude of doctors towards the use of thermometers in general practice.

\section{The Surgery, Park Road, Camberley, Surrey Steven Clarke, general practitioner trainee}

Correspondence to: Dr Steven Clarke, The Surgery, Fleet, Hampshire GU13 8JX.

$B M \mathcal{F} 1992 ; 304: 961-3$

\section{Methods}

One hundred and forty five general practitioners in the catchment area of Frimley Park Hospital, Surrey, were sent a two page postal questionnaire in April 1991. The subjects included all general practitioners on an up to date mailing list from the hospital's postgraduate medical centre.

The questionnaire asked doctors to state which type of thermometer they used and how often they had used it in the previous six months. Doctors were asked what factors might affect an oral temperature reading and how long, on average, they thought they left their thermometer in a patient's mouth. They were asked whether they thought axillary temperatures correlated well with oral and rectal temperatures and in what circumstances they considered taking a rectal temperature reading. Doctors were then asked whether they thought mothers and doctors were reasonably good at subjectively assessing the presence of a fever in children. They were asked to list those circumstances in which they felt the use of a thermometer was either useful or essential and to indicate how they cleaned their thermometers after use.

One month after the first questionnaire was sent those doctors who had failed to respond were sent a second questionnaire.

\section{Results}

A total of 116 replies were received, representing a response rate of $80 \%$. Table I shows the types of thermometers used. It shows a tendency towards the use of mercury glass thermometers, although electronic digital thermometers were also frequently used. Seven doctors $(6 \%)$ admitted to not having any method of taking a patient's temperature. Some doctors used more than one method of taking a patient's temperature and, in addition to the figures given in table I, 17 doctors had use of a low reading thermometer and seven had use of a fever detector strip.

TABLE I-Types of thermometer used by 116 general practitioners

\begin{tabular}{lc}
\hline Type of thermometer & No (\%) of doctors \\
\hline Mercury glass & $80(69)$ \\
Electronic digital & $16(14)$ \\
Both mercury glass and electronic digital & $11(9)$ \\
Fever detector strip & $2(2)$ \\
No method & $7(6)$
\end{tabular}

Table II shows the estimated frequency of use of thermometers in the six month period preceding completion of the questionnaire. Three general practitioners failed to answer this part of the questionnaire. As the results show a wide variation in the use of thermometers they have been presented in four groups: those doctors who had not used thermometers at all; those who had used them infrequently, less than once a fortnight (less than 12 times in six months); those who had used them between once a fortnight and twice a week (12-52 times in six months); and those who had used them frequently, more than twice a week (more than 52 times in 6 months). There was no apparent

TABLE II-General practitioners' estimates of use of thermometer in six months. Figures are numbers (percentage) of 113 doctors replying

\begin{tabular}{lcccc}
\hline & Not at all & $1-12$ Times & $12-52$ Times & $\begin{array}{c}\text { More than } \\
52 \text { times }\end{array}$ \\
\hline In surgery & $15(13)$ & $56(50)$ & $20(18)$ & $22(19)$ \\
On visits & $19(17)$ & $56(50)$ & $26(23)$ & $12(11)$ \\
\hline
\end{tabular}


difference between the use of thermometers in surgery time or on visits and no apparent difference between the use of mercury glass thermometers or electronic digital thermometers.

General practitioners were asked to give an estimate of how long they kept their mercury glass thermometer in a patient's mouth. Of the 80 doctors who used this method of taking a patient's temperature, $13(16 \%)$ left them in place for 30 seconds, $29(36 \%)$ for 1 minute, four $(5 \%)$ for 1.5 minutes, $24(30 \%)$ for 2 minutes, and six $(8 \%)$ for 3 minutes.

A total of $94(81 \%)$ doctors noted that food and drink might affect oral temperature readings. Only 37 (32\%) noted that mouth breathing may do so also.

Sixty three doctors (54\%) claimed that they would consider taking rectal temperature in infants and 35 $(30 \%)$ doctors said that they would take one in those patients suspected of having hypothermia. Twenty three doctors (20\%) thought that there was no place for rectal temperatures in general practice. There was no consensus as to whether axillary temperatures correlated well with oral and rectal temperatures: 47 doctors felt that they did whereas 62 doctors felt that they did not.

Table III shows that the majority of doctors feel that mothers and doctors are good at subjectively assessing the presence of fever in children and adults.

TABLE III-Subjective assessment of fever by mothers and general practitioners

\begin{tabular}{lcc}
\hline & \multicolumn{2}{c}{$\begin{array}{c}\text { No }(\%) \text { of doctors replying } \\
(\mathrm{n}=116)\end{array}$} \\
\cline { 2 - 3 } & Yes & No \\
\hline $\begin{array}{c}\text { Are mothers good at subjectively assessing the } \\
\text { presence of fever in their children? }\end{array}$ & $78(67)$ & $38(33)$ \\
$\begin{array}{l}\text { Are doctors good at subjectively assessing the } \\
\text { presence of fever in adults? }\end{array}$ & $76(66)$ & $36(31)$ \\
$\begin{array}{c}\text { Are doctors good at subjectively assessing the } \\
\text { presence of fever in children? }\end{array}$ & $96(83)$ & $18(16)$ \\
\hline
\end{tabular}

Table IV shows the methods used to clean thermometers after use. Most doctors cleaned them under tap water with or without soap or used an alcohol wipe. Only one doctor used thermometer sheaths, and six doctors admitted to not cleaning their thermometers between patients.

TABLE IV-Methods used to clean thermometers

\begin{tabular}{lc}
\hline Method & No (\%) of doctors \\
\hline Rinsing under tap with or without soap & $41(38)$ \\
Alcohol swab & $41(38)$ \\
Soaked in sodium hypochlorite solution (Milton) & $13(12)$ \\
Washed with chlorhexidine (Hibitane) & $5(5)$ \\
Thermometer sheaths & $1(1)$ \\
Not cleaned & $6(6)$ \\
\hline
\end{tabular}

The last part of the questionnaire invited general practitioners to identify some of the circumstances in which they thought the use of a thermometer was either useful or essential. Because it was an open ended question there was a great variety of responses and not all doctors gave an answer. In all, 38 doctors thought they were useful in the assessment of patients with abdominal pain, and 15 doctors found them useful in the assessment of patients with respiratory symptoms such as cough and wheeze. Many other clinical situations were suggested and several anecdotes were given: two doctors, for example, used thermometers to gain valuable thinking time; two used them to keep a patient quiet; and one pointed to the need for taking a patient's temperature for medicolegal reasons. Three doctors also pointed out their concerns regarding the use of thermometers by families, especially the increasing use of fever detector strips, which in their opinion were causing excessive anxiety in parents and precipitated unnecessary out of hours calls by their doctors.

\section{Discussion}

An $80 \%$ response rate is good for a postal questionnaire. Although the views of non-respondents were not formally assessed, the good response rate makes it likely that the results offer a fair representation of the attitudes of doctors.

Seven doctors admitted to not having any method of taking a patient's temperature and several more admitted to not using them in the previous six months. As some doctors use their thermometers frequently, up to two to three times a day, this reveals an enormous variation in the use of thermometers in general practice. Since the predictive value of temperature readings is not known it is difficult to draw any further conclusions from these results.

The mercury glass thermometer was the type most commonly used. Of those doctors who had used this method, only $8 \%$ kept their thermometers in a patient's mouth for three minutes. Coggon and Vessey have noted that it takes three minutes for a mercury glass thermometer to stabilise, ${ }^{1}$ and others have suggested even longer times. ${ }^{2}$ In a study by the East of Ireland Faculty of the Royal College of General Practitioners, 30 of 164 doctors (19\%) kept their thermometers in place for 3 minutes. ${ }^{3}$ In that study doctors were asked to time how long they kept thermometers in place, and this in itself may have encouraged longer times. None the less, both studies suggest that mercury glass thermometers are kept in place for three minutes in only a minority of instances.

Electronic digital thermometers take less than one minute to gain a reading. There have been variable reports regarding their accuracy ${ }^{48}$; they may be as accurate as mercury glass thermometers. If general practitioners are prepared to keep a thermometer in place for only up to a minute $(52 \%$ of doctors in this study) then electronic digital thermometers may be more accurate.

Nine doctors had use of fever detector strips, two of whom did not have any other method of taking a patient's temperature. Several studies have assessed the accuracy of fever detector strips ${ }^{9.14}$ and most have shown them to be inaccurate. In this study three doctors raised their concerns regarding their use, particularly by families.

This study has failed to identify the role of rectal temperature readings in general practice. Although 23 doctors felt that there was no place for them at all, others thought that they would use the technique in infants and in patients suspected of having hypothermia, though more doctors said that they would take a rectal temperature in cases of suspected hypothermia than had a low reading thermometer.

This study has also failed to identify the role of axillary temperature readings in general practice. Doctors were not asked how frequently they used the technique nor in which circumstances. The results did, however, reveal an interesting difference of opinion as to whether doctors thought axillary temperature readings correlated well with oral or rectal temperature readings. Studies looking into this issue have also failed to give an answer. Shann and Mackenzie achieved a correlation of $0.9^{15}$ but others failed to confirm this. ${ }^{16} 17$

Most doctors in this study considered both mothers and doctors to be reasonably good at detecting the presence of fever in children. Doctors felt confident in their own ability to do this. Evidence does not support this overall impression. Banco and Veltin found that mothers who said their children were febrile were 
correct in only $52 \cdot 3 \%$ of cases, and $10 \%$ of children with a temperature of $38.9^{\circ} \mathrm{C}$ or higher were incorrectly identified as being afebrile. ${ }^{18}$ Other studies found that nurses and doctors were also poor at identifying the presence of fever in children. ${ }^{319}$

General practitioners clean their thermometers in a variety of ways, and several doctors admitted to not cleaning them at all. This raises concern for the risk of cross infection. One doctor used thermometer sheaths, which are placed over the thermometer before use and disposed of after use. I am not aware of any studies that have looked into the effect of these thermometer sheaths on the accuracy of the temperature readings.

A doctor might take a patient's temperature for many reasons, but no conclusions can be made as to their importance. One reason brought to light in this study is medicolegal; however, the secretary of one of the defence societies was unable to give any examples of a doctor being found negligent simply for failing to take a patient's temperature. He did qualify this by stating that doctors may be questioned very closely about their reasons for not taking a patient's temperature and, taken with other factors, this may swing a decision for disciplinary proceedings against the doctor.

I thank Dr Nigel Hague for his help and support.
1 Coggon DNM, Vessey MP. Errors in using clinical thermometers. BMF 1976;i:692.

2 Temperatures and their accuracy. Nursing Times 1971;67:1139.

3 East of Ireland Faculty RCGP and Department of Community Health TCD. How good are we at guessing fever? Irish Med f 1986;79:15-6.

4 Ogren JM. The inaccuracy of axillary temperatures measured with an electronic thermometer. Am f Dis Child 1990;144:101-11.

Norris J. Taking temperatures: the changing state of the art. Contemp Paediat $1985 ; 2: 22-39$

6 Comparing thermometers. Nursing Care 1977;10:14-9.

7 Knapp HA. Accuracy of glass clinical thermometers compared to electronic thermometers. Am f Surg 1966;112:139-41.

8 Ferguson GT, Gohrke C, Mansfield L. The advantages of the electronic thermometer. Hospital 1971;45:62-3.

9 Scholefield JM, Gerba MA, Dwyer P. Liquid crystal forehead thermometer strips. Am $\mathcal{F}$ Dis Child 1982;136:198-210.

10 David CB. Liquid crystal forehead temperature strips. Am $f$ Dis Child 1983;137:87.

11 Lewit EM, Marshall CK, Salzer JE. An evaluation of a plastic strip thermometer. FAMA 1982;247:321.

12 Martyn KK, Urbano MT, Hayes JS. Comparison of axillary, rectal and skin based temperature assessment in preschoolers. Nurse Pract 1988;13:31.

13 Sharp GB. Fever detector strip criticised, defended. Nurse Pract 1988 July:9.

14 Reisanger KS, Kao J, Grant DM. Inaccuracy of the clinitemp skin thermometer. Paediatr 1979;64:4-6.

15 Shann F, Mackenzie A. Axillary or rectal temperature, in children? Lancet $1981 ; \mathrm{i}: 310$

16 Barrus D. A comparison of rectal and axillary temperatures by electronic thermometer measurements in preschool children. Paediatr Nurse 1983;9: 1010-1.

17 Kresh MJ. Axillary temperatures as a screening test for fever in children. J Paediatr 1984;104:596-9.

18 Banco L, Veltri D. Ability of mothers to subjectively assess the presence of fever in their children. Am $\mathcal{F}$ Dis Child 1984;138:976-8.

19 Bergerson PS, Steinfeld MJ. How dependable is palpation as a screening method for fever? Clin Paediatr 1974;13:350-1.
Broomhill Health Centre, South Broomhill, Northumberland NE65 0SR

Paul A Creighton, general practitioner

Angela M Evans, practice nurse

Correspondence to:

Dr Creighton.

BMf 1992;304:963-6

\title{
Audit of practice based cervical smear programme: completion of the cycle
}

\author{
Paul A Creighton, Angela M Evans
}

\begin{abstract}
Objectives-To determine the effectiveness of a practice based cervical screening programme and the changing pattern of abnormal smear results and to improve the quality of care provided for patients.

Design-Audit of practice held data on cervical screening from 1980 to 1990 . Changes in the programme were made after analysis of first five years' data.
\end{abstract}

Setting-Mixed urban and rural practice of 10900 patients in Northumberland.

Subjects - Women aged 20-65 who had not had a hysterectomy.

Results-2356 (85.1\%) of the 2767 targeted women had a test during $1980-5$ and $2498(89.5 \%)$ of the 2790 women had a test during 1985-90. Inviting women aged $20-25$ to attend for a test increased coverage from $45.8 \%(146 / 319)$ in $1980-5$ to $82.5 \%(282 / 342)$ in 1985-90. The proportion of women with abnormalities requiring hospital referral rose in the second half of the study, especially among younger women (from $17 / 39(44 \%)$ to $45 / 64(70 \%)$ in women aged $25-34)$.

Conclusions-Practice based cervical screening programmes can be highly effective. Cytological abnormalities affect patients psychologically as well as physically and practices should provide support and explanation for patients with abnormal results. Data from individual practices should be aggregated to allow health authorities to plan secondary care effectively.

\section{Introduction}

Over 2000 women every year die of carcinoma of the cervix. In England and Wales there were 13 times as many registrations of carcinoma in situ for $1981-3$ as there were for 1963-5 in women aged 25-34. ${ }^{1}$ Invasive squamous cell carcinoma of the cervix is responsible for an increasing number of deaths among these younger women. Although most deaths from invasive carcinoma of the cervix occur in women over 60 , in the three years 1986-9, 39 women died of cervical carcinoma in Northumberland, 21 of whom were under $65 .^{2}$

Our practice comprises a partnership of six doctors with one vocational trainee and is responsible for a total list of 10900 patients distributed in a mixed urban and rural area, occupying a $22.5 \mathrm{~km}$ (14 mile) strip of the Northumberland coast. Each doctor operates a personal list system within the umbrella of the partnership. The split site practice has a health centre in the town of Amble (four doctors) and the village of Broomhill (two doctors).

The practice population is stable (less than $5 \%$ turnover) and there has been little increase in the practice list size in the past 40 years. Most of our patients are in social class II-III, with a significant minority in social class $\mathrm{V}$. The area was largely dependent on mining until the closure of Broomhill colliery in 1964. The local miners, who were initially re-employed at smaller local collieries, have gradually become redeployed in the building trade and light industry. The number of long term unemployed people remains higher than the average for the rest of Northumberland.

The practice implemented a comprehensive screening programme for the detection of cervical abnormalities in 1980. The aims of the programme were to reduce the mortality and morbidity from carcinoma of the cervix by ensuring all women aged 25-65 had a cervical smear test once every five years. We conducted this audit to compare the number of women who had a smear test with the number of women targeted by the cervical smear policy to explore our suspicion that 